\title{
Teste de marcadores bioquímicos na identificação de prováveis indivíduos homozigotos dominantes para o gene tobiano em cavalos Pampa
}

[Biochemical markers test to identify probable homozygous dominant for the tobiano gene in Pampa horses]

\author{
E.G.A.C. Coelho ${ }^{1,4}$, D.A.A. Oliveira ${ }^{2}$, E.G. Cothran ${ }^{3}$, C.S. Teixeira ${ }^{2}$, R.L. Nunes ${ }^{2}$ \\ ${ }^{1}$ Aluno de pós-graduação - EV-UFMG - Belo Horizonte, MG \\ ${ }^{2}$ Escola de Veterinária - UFMG \\ Caixa Postal 567 \\ 30123-970 - Belo Horizonte, MG \\ ${ }^{3}$ Equine Genetics Lab. VIBS - CVM Texas A\&M University \\ ${ }^{4}$ Bolsista da CAPES
}

\begin{abstract}
RESUMO
Utilizaram-se 195 cavalos Pampa e um grupo-controle de 41 cavalos da raça Paint, provenientes de plantéis de várias regiões brasileiras, com o objetivo de avaliar a eficiência do teste mediante uso de marcadores bioquímicos: albumina ( $\mathrm{Al}$ ) e proteína de ligação da vitamina $\mathrm{D}(\mathrm{Gc})$, para identificação dos possíveis indivíduos homozigotos dominantes para o padrão de pelagem tobiano nos cavalos Pampa. Não foram encontrados genótipos $\mathrm{Al}^{\mathrm{BB}} \mathrm{e} \mathrm{Gc}^{\mathrm{SS}}$, revelando indício de quebra de ligação gênica entre tais locos e o loco tobiano e a ineficácia do teste bioquímico na detecção dos prováveis indivíduos homozigotos dominantes para o padrão de pelagem tobiano nos cavalos Pampa.
\end{abstract}

Palavras-chave: cavalo Pampa, cavalo Paint, tobiano, marcador genético, albumina, proteína de ligação da vitamina D (Gc)

\begin{abstract}
One hundred and ninety five Pampa horses and a control group of 41 Paint Horses originated from herds located in different Brazilian regions were used to objective of evaluate the efficiency of the biochemical markers albumin (Al) and vitamin D binding protein $(G c)$ to identify the probable homozygous dominant for the tobiano coat color pattern in Pampa horses. It was not found any genotype $A l^{B B}$ and $G c^{S S}$, indicating a possible break of the genetic linkage between these loci and the locus Tobiano, as well as the inefficacy of the biochemical test in the detection of the probable homozygous dominant for the tobiano color pattern in Pampa horses.
\end{abstract}

Keywords: Pampa horse, Paint horse, tobiano, genetic markers, albumin, vitamin D biding protein (Gc)

\section{INTRODUÇÃO}

O cavalo Pampa é oriundo do cruzamento entre reprodutores e reprodutrizes, das raças AngloÁrabe, Campeiro, Campolina, Crioulo, Mangalarga, Mangalarga Marchador e Puro Sangue Inglês (Andrade, 2004).

Recebido em 7 de julho de 2006

Aceito em 14 de abril de 2007

* Autor para correspondência (corresponding author)

E-mail: denise@vet.ufmg.br
Na pelagem pampa (tobiano), ocorrem malhas brancas despigmentadas e bem delimitadas, conjugadas com qualquer outra pelagem. Essas estão presentes desde o nascimento do indivíduo e são estáveis em toda a sua vida. Geralmente os cavalos tobiano têm cascos claros e as manchas do corpo cruzam a linha superior do tronco em algum lugar entre as orelhas e a cauda. As manchas brancas quase sempre atingem o dorso 
e as áreas brancas tendem a apresentar bordas definidas e dispostas verticalmente. Em geral as orelhas são pigmentadas e os olhos escuros. A cabeça tende a ser a última parte a ser coberta pelo branco, logo, cavalos tobianos com grande proporção de áreas despigmentadas, têm o corpo todo branco e a cabeça colorida, ou seja, a cabeça usualmente não tem mais branco do que o esperado em um cavalo não manchado.

Os cavalos tobianos apresentam pelo menos uma, se não todas as patas despigmentadas (Bowling, 1996; Sponenberg, 1996; Rezende e Costa, 2001; Belda, 1995; Brooks et al., 2002; Sponenberg, 2003). Em muitos cavalos com padrão tobiano, a pele pigmentada estende-se por uma pequena distância para dentro das áreas despigmentadas. $\mathrm{O}$ resultado é uma sombra ou halo entre as áreas coloridas e despigmentadas (Sponenberg, 1996). Esses padrões característicos servem para distinguir os cavalos tobiano de outros padrões de pelagens manchadas, tal como apalusa ou oveira, exceto quando dois ou mais padrões de manchas ocorrem no mesmo cavalo (Trommershausen, 1978).

O padrão de pelagem tobiano é causado pelo alelo tobiano (To), transmitido de forma mendeliana simples e herdado como um gene dominante. Em várias raças de cavalos, o loco To é ligado a locos que codificam as proteínas séricas albumina $(\mathrm{Al})$ e proteína de ligação da vitamina D (Gc) (Sponenberg, 1996). O cromossomo contendo o alelo tobiano usualmente possui um haplótipo com os alelos $\mathrm{Al}^{\mathrm{B}}$ e $\mathrm{Gc}^{\mathrm{S}}$. Essa ligação pode ser usada para identificar o indivíduo homozigoto para o gene To, cujo genótipo será $\mathrm{Al}^{\mathrm{BB}}$. $\mathrm{Gc}^{\mathrm{SS}}$, ToTo. No entanto, exceções a esta fase de ligação foram demonstradas em algumas raças (Duffield e Goldie, 1998).

Considerando a importância da detecção dos homozigotos (To) para cavalos Pampa, este trabalho teve como objetivo avaliar a eficiência do teste pelo uso dos marcadores bioquímicos (Al e Gc) na identificação de tais indivíduos.

\section{MATERIAL E MÉTODOS}

Foram colhidas amostras de soro sangüíneo, para análises laboratoriais das proteínas séricas albumina e Gc de 195 cavalos Pampa, reprodutores machos e fêmeas, bem como de sua progênies, registrados pela Associação Brasileira de Criadores de Pampa (ABCPAMPA), provenientes de vários plantéis, de diferentes regiões brasileiras. Foi utilizado um grupocontrole, composto por 41 cavalos da raça Paint testados no Laboratório de Genética da Escola de Veterinária da UFMG, em 2004 e 2005.

Os animais foram fotografados para revisão do padrão de pelagem informado dos mesmos.

As amostras de sangue foram colhidas em tubos a vácuo, sem anticoagulante, estéreis no volume de $5,0 \mathrm{ml}$ e armazenadas sob refrigeração a $4^{\circ} \mathrm{C}$. $\mathrm{O}$ material foi centrifugado a 4.400RPM, para separação do soro, o qual foi transferido para tubos plásticos. O material obtido foi, então, dividido em alíquotas e armazenado em freezer a $-20{ }^{\circ} \mathrm{C}$.

Posteriormente, foram submetidas à eletroforese em gel de amido e eletroforese em gel de poliacrilamida (PAGE), para separação e identificação dos alelos presentes nas proteínas albumina e Gc. Na preparação dos géis de amido para a albumina, foi utilizado o método desenvolvido por Scott (1970). Para o gel de PAGE, a técnica empregada foi a de Juneja et al. (1978).

Após a coloração, os géis foram analisados com auxílio de transiluminador de luz branca e fotografados ${ }^{1}$.

As freqüências alélicas e genotípicas foram estimadas por contagem direta. Para se avaliar a eficiência do teste dos marcadores bioquímicos para o Pampa, foi realizado um estudo de dispersão de freqüência usando-se o teste de quiquadrado $(\mathrm{P}<0,05)$, segundo Sampaio (1998).

\section{RESULTADO E DISCUSSÃO}

Para o sistema albumina, os alelos A e B foram identificados para os 195 cavalos Pampa e para os 41 cavalos Paint, identificando-se os genótipos $\mathrm{AA}, \mathrm{AB}$ e $\mathrm{BB}$ (Fig.1).

O cavalo Pampa apresenta uma grande etnodiversidade de raças que lhe deram origem

${ }^{1}$ Sony Digital Mavica - MVC -FD5 
(Beck, 2004), porém as raças Campolina, Mangalarga e Mangalarga Marchador têm maior participação no processo da sua formação. Nunes et al. (2005) observaram na raça Campolina maior freqüência do alelo B $(0,775)$ e Lippi e Mortari (2003), freqüências de 0,710 do alelo A na raça Mangalarga e 0,479 na raça Mangalarga Marchador. Para o cavalo Pampa, foi observada alta freqüência (Tab.1) do alelo A $(0,7667)$. Para este loco, tal resultado pode ser explicado pelo uso intensivo de alguns reprodutores da raça Mangalarga na formação do Pampa. Este resultado encontrou apoio na ABCPAMPA, conforme os registros dos animais amostrados. Nos cavalos Paint, foi observada alta freqüência do alelo B $(0,8659)$.

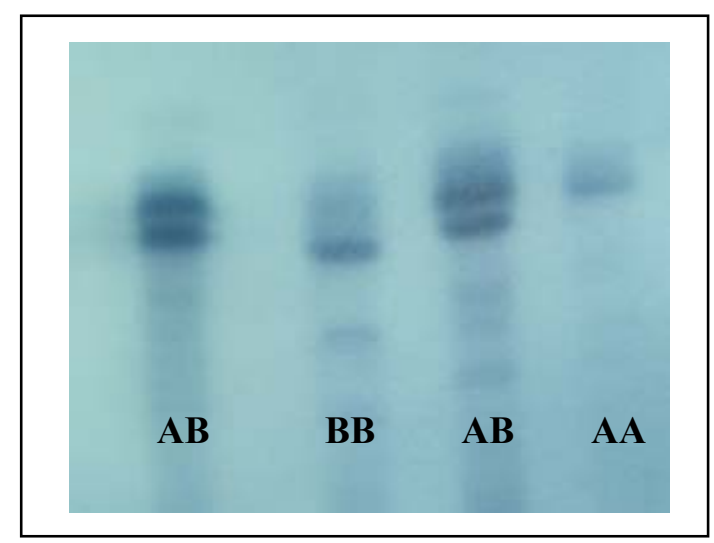

Figura 1 - Genótipos observados no gel de amido corado com Naftol Blue Black, para o sistema protéico albumina, nos cavalos Pampa e Paint. EV-UFMG - 2004 e 2005.

Para o sistema Gc, tanto nos Pampa quanto nos Paint foram identificados os alelos $F$ e $S$, observando-se os genótipos FF, FS e SS (Fig.2). Nos cavalos Pampa, foi encontrada alta freqüência do alelo F $(0,9385)$. Esses dados, mais uma vez, estão de acordo com os resultados de Lippi e Mortari (2003), que observaram alta freqüência alélica de $\mathrm{F}$ nos cavalos Mangalarga $(0,990)$ e Mangalarga Marchador $(0,960)$. Verificou-se alta freqüência do alelo $S(0,7683)$ para os cavalos Paint (Tab. 1).

As freqüências observadas e esperadas para os locos que codificam a albumina e Gc nos animais Pampa mostraram diferença significativa para o que se esperaria no equilíbrio de HardyWeinberg (Tab.2), revelando um excesso do genótipo AAFF. Essa população não mostrou nenhum genótipo BBSS como era esperado para os prováveis indivíduos tobianos homozigotos dominantes, indicando quebra da ligação gênica entre tais locos.

Para os cavalos Paint, também houve diferença significativa para o que se esperaria do equilíbrio de Hardy-Weinberg (Tab. 3), porém a explicação para o excesso do genótipo BBSS dá-se pelo fato de as amostras estudadas serem provenientes da rotina laboratorial no teste oferecido à Associação Brasileira dos Criadores de Cavalo Paint, para identificação dos homozigotos tobianos. Neste caso, eram amostras com grande possibilidade de serem homozigotas (BBSS).

Tabela 1. Freqüências gênicas para albumina e Gc nos cavalos Pampa e Paint, EV-UFMG 2006

\begin{tabular}{lccc}
\hline Sistema & Alelo & Pampa & Paint \\
\hline Albumina & A & 0,7667 & 0,1341 \\
& B & 0,2333 & 0,8659 \\
Gc & F & 0,9385 & 0,2317 \\
& S & 0,0615 & 0,7683 \\
\hline
\end{tabular}

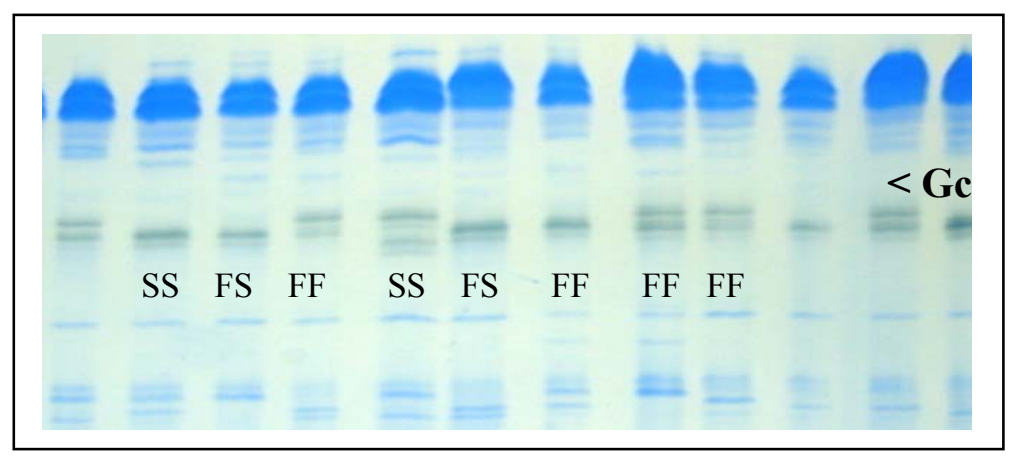

Figura 2. Genótipos observados no gel PAGE corado com Coomasie Blue para o sistema protéico Gc, nos cavalos Pampa e Paint, EV-UFMG - 2004 e 2005. 
Tabela 2 Freqüências genotípicas para albumina e Gc nos cavalos Pampa, EV-UFMG - 2006

\begin{tabular}{ccc}
\hline Genótipo & $\begin{array}{c}\text { Freqüência } \\
\text { observada }^{1}(\%)\end{array}$ & $\begin{array}{c}\text { Freqüência } \\
\text { esperada }(\%)\end{array}$ \\
\hline AAFF & 52,82 & 6,25 \\
AAFS & 2,05 & 12,50 \\
AASS & 0,00 & 6,25 \\
ABFF & 34,87 & 12,50 \\
ABFS & 8,72 & 25,00 \\
ABSS & 0,00 & 12,50 \\
BBFF & 1,03 & 6,25 \\
BBFS & 0,51 & 12,50 \\
BBSS & 0,00 & 6,25 \\
\hline $\mathrm{X}^{2}=872,15(\mathrm{P}<0,001) .{ }^{1}$ Total de 195 animais.
\end{tabular}

Tabela 3. Freqüências genotípicas para albumina e Gc nos cavalos Paint, EV-UFMG - 2006

\begin{tabular}{c|c|c}
\hline Genótipo & $\begin{array}{c}\text { Freqüência }^{\text {observada }^{1}(\%)} \\
\text { AAFF }\end{array}$ & $\begin{array}{c}\text { Freqüência } \\
\text { esperada (\%) }\end{array}$ \\
AAFS & 0,00 & 6,25 \\
AASS & 0,00 & 12,50 \\
ABFF & 0,00 & 6,25 \\
ABFS & 24,39 & 12,50 \\
ABSS & 2,44 & 25,00 \\
BBFF & 0,00 & 12,50 \\
BBFS & 24,39 & 6,25 \\
BBSS & 48,78 & 12,50 \\
\hline $\mathrm{X}^{2}=32,70,(\mathrm{P}<0,001)$. & \multicolumn{1}{|l}{ Total de 41 animais. }
\end{tabular}

O fato de não terem sido encontrados genótipos $\mathrm{Al}^{\mathrm{BB}}, \mathrm{Gc}^{\mathrm{SS}}$ nos cavalos Pampa, porém $48,8 \%$ dos animais $\mathrm{Al}^{\mathrm{BB}}, \mathrm{Gc}^{\mathrm{SS}}$ na raça Paint revela indícios de quebra de ligação gênica entre os locos $\mathrm{Al}$ e Gc com o loco To nos cavalos Pampa. Esse fato poderia ser explicado pela diferente origem das raças. A raça Paint, formada nos Estados Unidos da América a partir da não concessão de registros pela American Quarter Horse Association àqueles animais que possuíam manchas brancas no corpo, é uma raça mais antiga e homogênea que a Pampa. Esta possui uma grande etnodiversidade na sua formação, (Andrade, 2004), daí a elevada possibilidade de novas combinações genéticas.

\section{CONCLUSÕES}

Há evidências de quebra de ligação no grupo de ligação II do eqüinos (LGII) para os locos que codificam as proteínas séricas albumina, proteína de ligação da vitamina D e o padrão de pelagem tobiano, nos cavalos Pampa. O teste de marcador genético por meio das proteínas séricas albumina e proteína de ligação da vitamina D é ineficiente para se identificar os prováveis indivíduos homozigotos dominantes tobiano nos cavalos Pampa.

\section{AGRADECIMENTOS}

Os autores agradecem à Associação Brasileira de Criadores de Cavalo Pampa (ABCCPAMPA), pela colaboração na realização deste trabalho

\section{REFERÊNCIAS BIBLIOGRÁFICAS}

ANDRADE, L.S. Origens do Pampa. Disponível em: <http://www.abcpampa.org.br> Acessado em 7 jul 2004.

BECK, S.L. Pampa, raça ou pelagem? Disponível em: <http://www.abcpamp.org.br> Acessado em 7 jul. 2004.

BELDA, A.S. Caballos pintos y crítica de su veto para la Pura Raza Española. Av. Alim. Mej. Anim., v.35, p.13-24, 1995.

BOWLING, A.T. (Ed). Tobiano. In: Horse genetics. Wallingford: Cab International, 1996. p.43-58.

BROOKS, S.A. TERRY, R.B.; BAILEY, E. A PCR-RFLP for KIT associated with tobiano spotting pattern in horses. Anim. Gen., v.33, p.301-303, 2002.

DUFFIELD, D.A.; GOLDIE, P.L. Tobiano spotting pattern in horses: linkage of To with $\mathrm{Al}^{\mathrm{A}}$ and linkage disequilibrium. J. Her., v.89, p.104106, 1998.

JUNEJA, R.K.; GAHNE, B.; SANDBERG, K. Genetic polymorphism of vitamin $\mathrm{D}$ binding protein and another post-another post-albumin protein in horse serum. Anim. Blood Groups Bioch. Gen., v.9, p.29-36, 1978.

LIPPI, A.S.; MORTARI, N. Studies groups and protein polymorphisms in Brazilian horse breeds Mangalarga Marchador and Mangalarga (Equis caballus). Gen. Mol. Biol., v.2, p.431-434, 2003.

NUNES, R.L.; OLIVEIRA, D.A.A.; COELHO, E.G.A.C. Polymorphism of serum proteins in Campolina horses. Anim. Reprod., v.2, p.60-62, 2005. 
REZENDE, A.S.C.; COSTA, M.D. (Eds). Pelagem dos eqüinos: nomenclatura e genética, Belo Horizonte: FEP-MVZ, 2001. 106p.

SAMPAIO, I.B.M. (Ed). Estatística aplicada à experimentação animal. Belo Horizonte: FEPMVZ, 1998. 221p.

SCOTT, A.M. A single acid gel for the separation of albumin and transferrins in horse. Anim. Blood Groups Bioch. Gen., v.1, p.253-254, 1970.
SPONENBERG, D.P. (Ed). Patterns of white. In: Equine color genetics. Ames: Iowa State University, 1996. p.53-80.

SPONENBERG, D.P. The genetic equation. Disponível em $<$ http://www.apha.com/breed/geneticeq.html> Acessado em: 20 mai. 2003.

TROMMERSHAUSEN, S.A. Linkage of Tobiano coat spotting and albumin markers in a pony family. J. Her., v.69, p.214-216, 1978. 